\title{
Screening of Chlamydia trachomatis Infection in Men, Is It Necessary in Iran?
}

\author{
Bahram Fathollahzadeh ${ }^{1}$, Abbas Bahador ${ }^{1}$, Araz Majnooni ${ }^{2}$, Batool Kamalimanesh ${ }^{3}$, \\ Sedigheh Moshkani ${ }^{3}$, Morteza Haghighi Hasanabad ${ }^{3, *}$ \\ ${ }_{1}^{1}$ Department of Microbiology, School of Medicine, Tehran University of Medical Sciences, Tehran, IR Iran \\ ${ }^{2}$ Infectious and Tropical Disease Research Center, Tabriz University of Medical Sciences, Tabriz, IR Iran \\ ${ }^{3}$ Children and Pediatric Infection Diseases Research Center, Iran University of Medical Sciences, Tehran, IR Iran \\ ${ }^{*}$ Corresponding author: Morteza Haghighi Hasanabad, Children and Pediatric Infection Diseases Research Center, Iran University of Medical Sciences, Tehran, IR Iran. Tel/Fax: +98- \\ 2166516049, E-mail: mhaghighi.v@gmail.com
}

Received: October 12, 2012; Revised: December 22, 2012; Accepted: January 12, 2013

\begin{abstract}
Background: Chlamydia trachomatis is one of the most prevalent causative bacteria in sexually transmitted infections with adverse effects, which almost remain asymptomatic in society.

Objectives: This project designed to determine the prevalence of Chlamydial infection in men and comparing the related risk factors in two groups of referrals based on the study inclusion criteria.

Materials and Methods: Two hundreds of men who attended in the Mehrad hospital in Tehran Iran were selected and classified into two groups (symptomatic and asymptomatic). $10 \mathrm{~mL}$ of first void urine from each person collected and tested by polymerase chain reaction for the presence of $C$. trachomatis cryptic plasmid gene.

Results: In total, $8.5 \%$ of all subjects were positive (11\% of symptomatic and $6 \%$ of asymptomatic men). Statistical analysis revealed an association between condom usage as a variable and infection in asymptomatic group $(\mathrm{P} \leq 0.05)$.

Conclusions: Findings of this study show that Chlamydial infection screening especially in males with urogenital symptoms is necessary (at least in Tehran) and we recommend more epidemiological studies in other cities of Iran.

Keywords: Chlamydia trachomatis; Sexually Transmitted Infections; Men
\end{abstract}

\section{Background}

Today, sexually transmitted infections (STIs) are a main global public health problem which are among the 10 major causes of unpleasant disease in young adult men worldwide (1). While Chlamydia trachomatis (CT) known as a common bacterial cause of STIs with adverse effects (e.g. infertility), many countries have not national standard program for routine screening of male CT infections (2).

The development of current screening tests for noninvasive specimens (such as nucleic acid amplification tests (NAATs) in urine samples) with high accuracy and reliability, leads to early detection of infection in people and improvement of health outcomes in many countries (3). Infected men are more efficient in transmitting of CT to their partners with 40 to $64 \%$ spreading, compared with women that are about 21 to $35 \%$. Because of the burden of illness caused by asymptomatic chlamydial infections and their side effects $(4,5)$, detection of symptomatic/ asymptomatic infected men, identification of high risk people and contact tracing of men are part of attempts to prevention and control this infection (6).

\section{Objectives}

The main aim of this study was to determine the prevalence of chlamydial infection in men and general population to understand the necessity of screening and comparing the related risk factors in 2 groups.

\section{Material and Methods}

A total of 200 males who were sexually active (15 - 50 years old), referred to Mehrad hospital in Tehran, Iran were enrolled in this study. Participants were divided in two groups including symptomatic males with urogenital signs (symptoms referable to urinary-genital tract) and asymptomatic males with no genitourinary signs. The research ethics board at Tehran University of Medical Sciences approved this study and all participants signed a consent form. Exclusion criteria included antibiotic consumption in the past 3 weeks, catheter usage and illness severity that precluded study interview (7). Personal and clinical information including age, marital status, educational level, smoking habit, history of STIs, condom usage etc. was recorded in questionnaire.

Ten milliliter of First void urine (FVU) from each person

Implication for health policy/practice/research/medical education:

Screening of Chlamydia trachomatis in sexually active males with urogenital symptoms should be mandatory in Iran and laboratories should provide improved low-cost techniques to identify and confirm the infection.

Copyright (C) 2013, Ahvaz Jundishapur University of Medical Sciences; Published by Kowsar Corp. This is an open-access article distributed under the terms of the Creative Commons Attribution License, which permits unrestricted use, distribution, and reproduction in any medium, provided the original work is properly cited. 
who had not urination at least for the last 2 hours, were collected in a sterile container. Biochemical analysis was done with Dipstick test on $5 \mathrm{~mL}$ of urine and remained samples stored at $4^{\circ} \mathrm{C}$ for one night to reduce the inhibitors, then centrifuged (6000 g, 30 minutes) and pellets washed with phosphate buffer saline (PBS) twice (8). DNA was extracted using DNG-Plus (Cinnagen, Tehran, Iran) according to the manufacturer instructions and stored at $-70^{\circ} \mathrm{C}$ until use for polymerase chain reaction (PCR) (9). PCR with a final volume of $20 \mu \mathrm{L}(2 \mu \mathrm{L}$ of Master mix PCR solution, $0.5 \mu \mathrm{L}$ forward primer, $0.5 \mu \mathrm{L}$ reverse primer, $1 \mu \mathrm{L}$ DNA and $16 \mu \mathrm{L}$ water) performed over 30 cycles, including denaturation at $94^{\circ} \mathrm{C}$ for 40 seconds, annealing at $58^{\circ} \mathrm{C}$ for 45 seconds and extension at $72^{\circ} \mathrm{C}$ for 40 seconds, followed by a final extension step at $72^{\circ} \mathrm{C}$ for 8 minutes.

Each batch of diagnostic process was evaluated by positive and negative control (CT Serovar L2 ATCC VR 902 B and water respectively). PCR products were analyzed on $1 \%$ agarose gel through $0.5 \%$ TBE buffer and were visualized by ethidium-bromide under UV transilluminator. Statistical analyses were estimated using SPSS for windows (version 15. Chicago, Ltd, USA). Chi-square test with the level of significance defined as a $\mathrm{P} \leq 0.05$ and common odds ratio ( $95 \% \mathrm{CI}$ ) were used for possible association of variables. Table 1 shows the primers used in this study.
Table 1. Primer Sequences for Detection of Cryptic Plasmid Gene

\begin{tabular}{ll}
\hline Primer & Sequence \\
\hline KL1 Sequences & $5^{-}$-TCC GGA GCG AGT TAC GAA GA-3- \\
KL2 Sequences & $5^{-}$-AAT CAA TGC CCG GGA TTG GT-3' \\
\hline
\end{tabular}

\section{Results}

The prevalence of CT among 200 men recruited in this study was $8.5 \%$ (17/200). In total, $64.70 \%$ of the infected men were married and $52.9 \%$ of them were $\geq 25$ years old (mean age $=34$ years). Also the $58.8 \%$ of infected males had high school or diploma degree. The rate of infection in symptomatic participants was $11 \%$, the most common symptoms reported in this group were urethral discharge, urinary frequency and dysuria consecutively. Finally, in asymptomatic males who recruited randomly with no genitourinary signs or symptoms, 6 specimens (6\%) were positive.

No statistically significant difference was found between two groups applied in this study. Important medical variables, behavioral determinants and biochemical urinalysis of the men with positive CT infection are shown in Table 2, which also illustrates the results of statistical analysis for each group.

Table 2. Important Variables in Men With Chlamydial infection

\begin{tabular}{|c|c|c|c|c|c|}
\hline Cause & Yes, No. (\%) & No, No. (\%) & P value & 95\% CI & Odd's Ratio \\
\hline History of STIs & & & & 1.559 & $0.569-4.273$ \\
\hline $\mathrm{SM}^{\mathrm{a}}$ & $4(36.3)$ & $7(63.6)$ & $\mathrm{NS}^{\mathrm{a}}$ & & \\
\hline $\mathrm{AM}^{\mathrm{a}}$ & $3(50)$ & $3(50)$ & NS & & \\
\hline Smoking & & & & 0.504 & $0.139-1.832$ \\
\hline SM & $2(18.1)$ & $9(81.8)$ & NS & & \\
\hline $\mathrm{AM}$ & $1(16.6)$ & $5(83.3)$ & NS & & \\
\hline $\begin{array}{l}\text { Even Heard CT Infec- } \\
\text { tion }\end{array}$ & & & & 1.254 & $0.379-4.149$ \\
\hline SM & $3(27.2)$ & $8(72.7)$ & NS & & \\
\hline AM & $1(16.6)$ & $5(83.3)$ & NS & & \\
\hline Condom Usage & & & & 0.329 & 0.116-0.139 \\
\hline SM & $4(36.3)$ & $7(63.6)$ & NS & - & - \\
\hline $\mathrm{AM}$ & $2(33.3)$ & $4(66.6)$ & $\leq 0.05$ & - & - \\
\hline WBC in Urine ${ }^{b}$ & & & & - & - \\
\hline $\mathrm{SM}$ & $5(45.4)$ & $6(54.5)$ & NS & - & - \\
\hline $\mathrm{AM}$ & $2(33.3)$ & $4(66.6)$ & NS & - & - \\
\hline RBC in Urine $^{\mathrm{b}}$ & & & & - & - \\
\hline $\mathrm{SM}$ & $3(27.2)$ & $8(72.7)$ & NS & - & - \\
\hline AM & $1(16.6)$ & $5(83.3)$ & NS & - & - \\
\hline
\end{tabular}

a Abbreviations: AM, Asymptomatic Men; SM, Symptomatic Men; NS, Not Significant

$\mathrm{b}_{\text {Yes means High and No means few to moderate in Dipstick test }}$ 


\section{Discussion}

The most important aspect in diagnosis of STIs is maintaining a high level of awareness. Chlamydial infection is the most frequently reported STIs that at least $50 \%$ of infected men are asymptomatic and commonly coexist with gonorrhea infections. Also it is one of the causes of nongonococcal urethritis (10). Although people $<25$ years old are considered as a most prevalent group, but in this study, a high frequently of infection detected in men $\geq 25$ years old (52.9\%) which is maybe related to high old range of recruited people in this study.

Based on previous reports, the prevalence of Chlamydia infection in Iranian men differs from 6 to 10\% (11, 12). Our results are similar to two studies carried out in Tehran which reported that $8.8 \%$ and $8.4 \%$ of male patients were infected with CT $(13,14)$. In general, the reported prevalence was $4.19 \%$ in the United States and $2.6 \%$ in China which are lower than our result of asymptomatic males $(15,16)$. Also infection rates were about $12.4 \%$ and $13.1 \%$ among the male referred to STIs clinics in Kuwait and Brazil respectively which are higher than our findings (17, 18).

We found it noticeable that CT infection detected in males who did not use condom, are three times more than those who used condom $(\mathrm{OR}=0.33)$. This finding is similar to a study conducted in United States which indicated that condom usage is significantly associated with a $90 \%$ reduction in the total prevalence (19). Although there are established studies linking that high burden of illness occurrence by CT at high risk population and many recommendations for routine screening to reduce healthcare costs in society, but there is no strategy for screening of males in Iran. Finally, we found it reasonable to suggest that all sexually active males with any genitourinary symptoms be offered to screen the CT infection with sensitive and fast diagnostic assays such as NAATs.

\section{Acknowledgements}

There is no acknowledgments.

\section{Authors' Contribution}

Professor Bahram Fathollahzadeh and Dr. Abbas Bahador worked as supervisor and advisory professors consecutively. Dr. Araz Majnooni was the colleague member and contribution to the development of the protocol. Ms. Kamalimanesh and Ms. Moshkani were colleague members and contributed in drafting and preparing of the manuscript. Dr. Morteza Haghighi Hasanabad: Original Idea, Management of the protocol, Data analysis, Critical revision of the manuscript for important intellectual content.

\section{Financial Disclosure}

There is no financial disclosure.

\section{Funding/Support}

This project was supported by the Tehran University of Medical Sciences.

\section{References}

1. Da Ros CT, Schmitt Cda S. Global epidemiology of sexually transmitted diseases. Asian J Androl. 2008;10(1):110-4.

2. LaMontagne DS, Fenton KA, Randall S, Anderson S, Carter P. Establishing the National Chlamydia Screening Programme in England: results from the first full year of screening. Sex Transm Infect. 2004;80(5):335-41.

3. Amin Manal M, Emara Amany, El-Din Hala Bader, Elghandour Tarek MA. Detection of Neisseria Gonorrhea, Chlamydia trachomatis and Mycoplasma Genitalium in Acute Male Urethritis Using Multiplex PCR. 2007.

4. Bakhtiari A, Firoozjahi A. Chlamydia trachomatis infection in women attending health centres in Babol: prevalence and risk factors. East Mediterr Health J. 2007;13(5):1124-31.

5. Regional Strategy for the Prevention and Control of Sexually Transmitted Infections, 2007-2015.: World Health Organization; 2007.

6. Cates Jr Willard, Wasserheit Judith N. Genital chlamydial infections: epidemiology and reproductive sequelae. Am J Obst Gynecol.1991;164(6):1771-1781.

7. Leka TW, Patrick K, Benenson AS. Chlamydia trachomatis urethritis in university men: risk factors and rates. J Am Board Fam Pract. 1990;3(2):81-6.

8. Cheng H, Macaluso M, Vermund SH, Hook EW, 3rd. Relative accuracy of nucleic acid amplification tests and culture in detecting Chlamydia in asymptomatic men. J Clin Microbiol. 2001;39(11):3927-37.

9. Fatholahzadeh B, Bahador A, Haghighi Hasanabad M, Bazarjani F, Haghighi F. Comparative screening of Chlamydia trachomatis infection in women population in tehran, iran. Iran Red Crescent Med J. 2012;14(5):289-93.

10. Haghighi Hasanabad M, Mohammadzadeh M, Bahador A, Fazel N, Rakhshani H, Majnooni A. Prevalence of Chlamydia trachomatis and Mycoplasma genitalium in pregnant women of SabzevarIran. Iran J Microbiol. 2011;3(3):123-8.

11. Ghanaat J, Afshari JT, Ghazvini K, Malvandi M. Prevalence of genital Chlamydia in Iranian males with urethritis attending clinics in Mashhad. East Mediterr Health J. 2008;14(6):1333-7.

12. Meidani Mohesn, Chamani Tabriz Leili, Zeraati Hojjat, Razin Bahram, Jamali Bahareh, Gachkar Latif, et al. Molecular Assessment on the Prevalence of Urogenital Infection with Chlamydia Trachomatis in Asymptomatic Men.J Isfahan Med School. 2008;25(87):45-53.

13. Darougar S, Jones BR, Cornell L, Treharne JD, Dwyer RS, Aramesh B. Chlamydial urethral infection in Teheran. A study of male patients attending an STD clinic. BrJVener Dis. 1982;58(6):374-6.

14. Badami N. . Prevalence of chlamydia trachomatis in attendants to STD clinics of Tehran University of Medical Sciences. Tehran: Tehran University of Medical Sciences; 1992.

15. Parish WL, Laumann EO, Cohen MS, Pan S, Zheng H, Hoffman I, et al. Population-based study of chlamydial infection in China: a hidden epidemic. JAMA. 2003;289(10):1265-73.

16. Miller WC, Ford CA, Morris M, Handcock MS, Schmitz JL, Hobbs MM, et al. Prevalence of chlamydial and gonococcal infections among young adults in the United States. JAMA. 2004;291(18):2229-36.

17. Al-Sweih NA, Khan S, Rotimi VO. The prevalence of Chlamydia trachomatis and Neisseria gonorrhoeae infections among men with urethritis in Kuwait. J Infect Public Health. 2011;4(4):175-9.

18. Barbosa MJ, Moherdaui F, Pinto VM, Ribeiro D, Cleuton M, Miranda AE. Prevalence of Neisseria gonorrhoeae and Chlamydia trachomatis infection in men attending STD clinics in Brazil. Rev Soc Bras Med Trop. 2010;43(5):500-3.

19. Niccolai LM, Rowhani-Rahbar A, Jenkins H, Green S, Dunne DW. Condom effectiveness for prevention of Chlamydia trachomatis infection. Sex Transm Infect. 2005;81(4):323-5. 